\title{
Establishment of Clinical and Lab Algorithms for the Identification of Carriers of Mutations in CYP21A2 - A Study of 365 Children and Adolescents
}

\author{
Authors

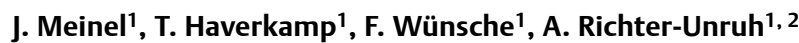

Affiliations

1 MVZ Dr. Eberhard \& Partner Dortmund (ÜBAG), Dortmund Germany

2 Ruhr-University Bochum, University Children's Hospital Bochum, St. Josef- Hospital, Department of Pediatric Endocrinology, Bochum Germany

Key words CYP21A2 gene, ACTH-test, Congenital adrenal hyperplasia, $170 \mathrm{HP}$ values

received 12.03 .2020

revised 16.06 .2020

accepted 08.07 .2020

published online $\quad 24.08 .2020$

Bibliography

Exp Clin Endocrinol Diabetes 2021; 129: 492-499

DOI 10.1055/a-1217-7169

ISSN 0947-7349

(c) 2020. Thieme. All rights reserved.

Georg Thieme Verlag KG, Rüdigerstraße 14,

70469 Stuttgart, Germany

\section{Correspondence}

Prof. Annette Richter-Unruh

Childrens Hospital, Ruhr University Bochum,

Alexandrinenstsr. 5

44801 Bochum

Germany

Tel.: 01737280863

richter-unruh@web.de

Supplementary Material for this article is available online at http://www.thieme-connect.de/products.

\section{ABSTRACT}

Background Mutations of CYP21A2 encoding 21-hydroxylase are the most frequent cause of congenital adrenal hyperplasia (CAH) and are associated either with elevated basal or ACTHstimulated levels of 17-hydroxyprogesterone (17OHP) in blood. Objective The study objective was to identify the most suitable of 12 different test algorithms and appropriate cut-off levels for that test to recognize patients with non-classical congenital adrenal hyperplasia (NCCAH) and carriers of clinically relevant mutations in CYP21A2.

Method and Patients Between July 2006 and July 2015 ACTHtests were conducted in 365 children and adolescents (Age 1-20y) suspected to have NCCAH. As a reference, results from subsequent gene sequencing of CYP21A2 was used. Inclusion criteria that were used were premature pubarche with accelerated bone age, hyperandrogenism, hirsutism, or menstrual irregularities. Receiver operating characteristics (ROC) were plotted. Evaluated test algorithms were composed around 17OHP measurements by radioimmunoassays. The most suitable test was identified by the greatest area under the curve (AUC).

Results Among the 12 tested algorithms, the sum of $30 \mathrm{~min}$ and 60 min stimulated $17 \mathrm{OHP}$ values (sum170HPstim) showed the highest AUC of 0.774 for identifying heterozygous and biallelic mutations. A cut-off of $10.1 \mu \mathrm{g} / \mathrm{l}$ was advisable. Bi-allelic mutations only were best identified calculating the difference between $30 \mathrm{~min}$ and basal $17 \mathrm{OHP}$ values $(\triangle 170 \mathrm{HP} 30)$. A cut-off of $9.4 \mu \mathrm{g} / \mathrm{l}$ was most effective.

Conclusion Alternatively to the above mentioned cut-offs the difference of $60 \mathrm{~min}$ after stimulation to basal $17 \mathrm{OHP}(\Delta 17 \mathrm{OHP} 60)$ can be used for the benefit of a combined test to identify both heterozygotes and bi-allelic patients. There are minimal decreases in sensitivity and specificity compared to an approach that applies two tests. However, it denotes a simpler approach in the clinical routine.

\section{Introduction}

Congenital Adrenal Hyperplasia (CAH) is one of the most common autosomal recessive disorders. In $95 \%$ of patients it is caused by a defect in the 21-hydroxylase enzyme encoding gene (CYP21A2) [1]. However, other enzyme defects are also possible as a cause of $\mathrm{CAH}$. As $\mathrm{CAH}$ is generally regarded as a recessive disorder, both parental alleles must be affected [2]. 21-hydroxylase is important in the pro- duction of aldosterone and cortisol from progesterone and $17 \alpha$-hydroxyprogesterone (170HP). As a consequence in 21-hydroxylase deficiency, adrenal androgens and above all the steroid and intermediate of androgen synthesis $170 \mathrm{HP}$ are produced in excess. Among other effects, elevated levels of androgens can lead to hyperandrogenism and virilisation in females. 
It is generally differentiated between classical and non-classical congenital adrenal hyperplasia (NCCAH). The classical form is caused by more severe enzyme defects, which lead to genital ambiguity at birth, and is further divided into the salt-wasting and non-salt-wasting form. The salt-wasting form leads to a potentially life-threatening loss of electrolytes and fluids (a salt-wasting crisis) in the first weeks after birth. NCCAH, also known as late-onset $\mathrm{CAH}$, often remains unrecognised at birth and only becomes more apparent later on in childhood or puberty. This happens due to accelerated bone age, premature pubarche or severe acne.

New-born screening exists in Germany and many other countries around the world to identify patients with classical CAH. Also a third of NCCAH patients that are identified in this way [3,4]. Nevertheless, this leaves a significant proportion of NCCAH patients undiagnosed. To identify patients with NCCAH or just heterozygous carriers, different methods exist. These either involve determining urine steroid profiles (USPs), conducting an ACTH-test and determining basal and post-stimulation blood steroid levels or preforming molecular genetic analysis. USPs are favourable due to their non-invasiveness, especially in younger patients, but the ACTH-test poses an advantage over USPs as it may be conducted within about an hour's time during a single visit to the medical practice. In order to determine the USP the collection of urine over the course of $24 \mathrm{~h}$ is necessary. Molecular genetic tests are the only way of reliably identifying all NCCAH and heterozygous carriers, but currently involve significant costs and thus an effective pre-selection process is desirable.

Different approaches to ACTH-tests and their evaluation have been mentioned in previous publications [5-10]. Some studies have reported on the use of ACTH stimulated 21-deoxycortisol to identify NCCAH patients and heterozygotes [5,11-13]. The results are especially promising when employing tandem mass spectrometry after high performance liquid chromatography separation (LCMS/MS) [14] rather than radioimmuneassays [5, 12]. LC-MS/MS is becoming increasingly available but publications are still limited and non-decisive as to which calculation to use for carrier identification $[14,15]$. Thus 21 -deoxycortisol values are not ubiquitously accessible in the clinical routine and require further research. $170 \mathrm{HP}$ presents a more common steroid used to distinguish NCCAH and heterozygotes but a medley of different approaches have been discussed. These include the use of basal 17OHP levels [16], conducting ACTH-tests and using stimulated 17OHP levels after $30 \mathrm{~min}$ [7] and $60 \mathrm{~min}[8,17]$; the difference (delta) between basal and stimulated (60 min) 170 HP levels $[9,18,19]$ and the sum of stimulated (60 min) and basal 170 HP levels [10]. This study aims at identifying the most suitable test as well as proposing cut-off values to identify heterozygous or homozygous patients using that specific test.

\section{Method}

In this retrospective study, anonymised clinical data collected between July 2006 and July 2015 in the Ruhr area of Germany was used. In total, 365 patients with symptoms indicating NCCAH were included in this study. NCCAH symptoms for inclusion were premature pubarche, accelerated bone age, hyperandrogenism as well as signs of androgenisation such as hirsutism and menstrual irregu- larities. The patients were above the age of one and up to and including the age of 20. All patients underwent an ACTH-Test and molecular genetic analysis of CYP21A2. When patients underwent two or more ACTH-Tests during the course of this study, only the most recent results were included. The $\mathrm{ACTH}$-Test was conducted using $250 \mu \mathrm{g}$ Synacthen, Novartis Pharma. Immediately before, 30 min after and 60 min after ACTH was administered, blood samples were collected and analysed. Tests were carried out in the morning and patients non-fasting. As an inclusion criterion for girls was irregular menstrual cycle, tests could not be performed during a specific known phase of the cycle. However, in patients with high levels of luteinizing hormone (LH), the ACTH test was repeated two weeks later to exclude measurements during the luteal phase. None of the patients was taking oral contraceptives.

The used data for this study included basal ACTH levels, basal $170 \mathrm{HP}$ levels as well as $170 \mathrm{HP}$ levels 30 and $60 \mathrm{~min}$ after ACTH was administered. Patients were only included when values of all three $170 H P$ measurements were known and the information was not pooled. Thus, associations between individual values remained to be known.

The result of the molecular genetic testing was regarded as gold standard to diagnose the presence or absence of CYP21A2 mutation status and furthermore used as such when calculating sensitivity and specificity.

The following twelve tests will be compared:

- Basal 170HP levels (170HPBasal)

- Stimulated $170 \mathrm{OP}$ levels 30 min after ACTH was given (170HP30)

- Stimulated 17OHP levels 60 min after ACTH was given (170HP60)

- Difference between 30 min stimulated and basal 17OHP levels ( $\triangle 170 H$ P30)

- Difference between 60 min stimulated and basal $170 H P$ levels $(\Delta 170 \mathrm{HP} 60)$

- Difference between $60 \mathrm{~min}$ and $30 \mathrm{~min}$ stimulated $170 \mathrm{HP}$ levels ( $\triangle 170 H$ Pstim)

- Sum of basal and 30 min stimulated $170 H P$ levels (sum170HP30)

- Sum of basal and 60 min stimulated $170 \mathrm{HP}$ levels (su$\mathrm{m} 170$ HP60)

- Sum of 30 min and 60 min stimulated 170HP levels (sum170HPstim)

- Quotient: 30 min stimulated 170HP divided by basal 17OHP (ratio170HP30)

- Quotient: 60 min stimulated 17OHP divided by basal 17OHP (ratio170HP60)

- Quotient: 60 min stimulated $170 H P$ divided by 30 min stimulated 170HP levels (ratio170HPstim)

Ratios of $170 \mathrm{HP}$ values have thus far only been proposed in the form of a nomogram [20]. This paper investigates a wide range of tests to find the most appropriate. Not all of them have been mentioned in previous publications or used in practice.

\section{7-OHP Measurements}

Serum samples were analysed using radioimmunoassay (RIA) 17-alpha-Hydroxyprogesteron RIA-CT (DIA-Source). The intra- and in- 
terassay coefficients of variation are $4.6 \%$ (at $1.94 \mathrm{ng} / \mathrm{ml}$ ) and $7.7 \%$ (at $2.08 \mathrm{ng} / \mathrm{ml}$ ) respectively [21]. During 2006 and 2015, the assay manufacturer and thus test characteristics did not change.

\section{Molecular genetic analysis}

The complete gene sequence of CYP21A2 from c. -400 to c. ${ }^{*} 179$, including coding exons $1-10$, all introns and relevant functional promoter elements starting with -400 and $3^{\prime}$ UTR to $c$. ${ }^{*} 179$, were amplified by 3 allele specific PCR amplicons (E1-3, E2-6, E3-10) employing sequence differences (8bp deletion, cluster mutation in E6) to the highly similar pseudogene CYP21A1, and screened for mutations by Sanger sequencing. A search for deletions/duplications of CYP21A2 and surrounding loci were added by MLPA methodology (Multiplex-Ligation-Dependent Probe Amplification; MRC-Holland, KIT P050, Lots B3 or C1). In patients presenting two different mutations, parents and siblings were offered genetic testing to exclude an allele carries mutations in cis. This mutation segregation was performed in 6 of the 8 patients with two differing mutations. All detected mutations were classified as mild or severe based on the database of the Pharmacogene Variation Consortium (PharmVar) [22]. A mutation was regarded as severe when causing salt-wasting or simple virilising $\mathrm{CAH}$ in homozygous state. Consequently, patients with bi-allelic mutations were divided into two groups (mild/mild; mild/severe) to asses, if harbouring a severe mutation correlated with more distinctive ACTH-Test results.

\section{Statistics}

Statistical analysis was conducted using SPSS v25. Differences in characteristics of patients with and without CYP21A2 mutations were evaluated using the $t$-test for continuous variables and the $x^{2}$ test for categorical variables. P-Values $<0.05$ were considered significant. For the comparison of different tests accuracies for identifying patients with mutations in the CYP21A2 gene, Receiver Operating Characteristics (ROC) were plotted. The calculation of an optimal cut-off point was performed using Pythagoras' theorem as described by Froud et al. [23].

\section{Results}

The studied patients were predominantly female, with females making up $88.8 \%$ of the cohort. No difference in mean age and gender distribution between the group with and without a CYP21A2 mutation could be observed ( $\vee$ Table 1). In contrast, mean 17OHP values before, 30 min and 60 min after the application of ACTH were significantly higher in the group carrying at least one mutated allele ( $\triangleright$ Table 1 ).
Molecular genetic analysis revealed one or more mutations in $83(22.7 \%)$ of the 365 patients. 8 patients had two or more different mild mutations and segregation analysis confirmed that mutations were located in trans on the CYP21A2 alleles of 5 patients and in cis in 1 patient. The 2 patients for where mutation segregation was not performed were assigned to the heterozygous group. 4 patients harboured mild homozygous mutations, thus 9 patients with bi-allelic mutations were found. These can be regarded as NCCAH patients. 4 patients were compound heterozygous for a classical (severe) and a non-classical (mild) mutation and 1 patient carried a combination of two mild mutations (mild/mild).

Of the 74 carriers of mono-allelic mutations 66 had single heterozygous point mutations, 4 had duplications, 3 had gene conversions and 1 person had a gene deletion as illustrated by $>$ Fig. 1. By far the most often detected mutation was p.Val281Leu in 33 patients, 3 of them homozygous. The second and third most frequently detected mutations were p.GIn318Stop and p.Pro453Ser with 14 and 8 patients respectively. A complete count of detected mutations and their attributed severity is shown in $>$ Table 2 .

Of the diagnostic tests investigated to identify patients with mutations affecting either one or both parental alleles of the CYP21A2 gene, the sum of $30 \mathrm{~min}$ and $60 \mathrm{~min}$ stimulated values (sum17OHPstim) showed the highest AUC of 0.774 ( $>$ Table 3 and $>$ Fig. 2). The test was closely followed by $170 \mathrm{HP} 30$ values and the difference between 60 min stimulated and basal values $(\triangle 170 H P 60)$ with AUCs of 0.772 and 0.771 respectively. Basal $170 \mathrm{HP}$ and all tests composed around calculating quotients were poor tests in this investigation, with AUC values below 0.6.

The optimal sum $170 H$ Pstim cut-off found using Pythagoras' theorem was identified to be $>10.1 \mu \mathrm{g} / \mathrm{l}$. The $>10.1 \mu \mathrm{g} / \mathrm{l}$ cut-off had a sensitivity $71.1 \%$ and a specificity $71.6 \%$. In the studied cohort 138 of the patients had a Sum 170 HPstim $>10.1 \mu \mathrm{g} / \mathrm{l} .24$ patients with mutations were not identified, which gave rise to a false negative rate of 0.289 . The cut-off shows a positive likelihood ratio $(L R+)$ of 2.50 and a negative likelihood ratio (LR-) of 0.40 . Thus, a patient above this cutoff is 2.5 times more likely to be positive for at least one CYP21A2 mutation than to be negative for the same, when genotyped.

Previously it has been suggested that one should use the $\triangle 170 H P 60$ test with a cut-off of $2.5 \mu \mathrm{g} / \mathrm{l}$ for this purpose [19]. In our investigation this cut-off showed a sensitivity and specificity of 92.8 and $25.2 \%$ respectively, therefore the LR + was just 1.24 and the LR- 0.29 .

To identify patients with bi-allelic mutations a number of tests that were conducted showed very high AUCs of 0.95 and above. In decreasing order these were $\triangle 170 H P 30, \triangle 170 H P 60$ and $170 H P 30$. The AUC of the most effective test, the difference between 30 min

- Table 1 Patient characteristics by mutation status.

\begin{tabular}{|l|l|l|l|c|}
\hline & $\begin{array}{l}\text { No CYP21A2 } \\
\text { Mutation }\end{array}$ & $\begin{array}{l}\text { All CYP21A2 } \\
\text { Mutation }\end{array}$ & $\begin{array}{l}\text { Only heterozygous } \\
\text { CYP21A2 Mutations }\end{array}$ & $\begin{array}{l}\text { Only bi-allelic CYP21A2 } \\
\text { Mutation }\end{array}$ \\
\hline $\boldsymbol{n}$ & $\mathbf{2 8 2}$ & $\mathbf{8 3}$ & $\mathbf{7 4}$ & $\mathbf{9}$ \\
\hline Females $(n, \%)$ & $253(89.7)$ & $71(85.5)$ & $62(83.8)$ & $9(100)$ \\
\hline Age in years $($ mean \pm SD) & $10.99 \pm 4.14$ & $10.08 \pm 3.87$ & $10.13 \pm 3.79$ & $9.69 \pm 4.71$ \\
\hline 17OHPBasal in $\mu \mathrm{g} / \mathrm{l}($ mean \pm SD) & $1.45 \pm 0.99$ & $3.20 \pm 7.73$ & $1.77 \pm 1.49$ & $14.89 \pm 20.51$ \\
\hline 17OHP30 in $\mu \mathrm{g} /$ (mean \pm SD) & $4.05 \pm 1.47$ & $10.17 \pm 15.71$ & $5.90 \pm 2.32$ & $45.29 \pm 30.39$ \\
\hline 17 OHP60 in $\mu \mathrm{g} /$ (mean \pm SD) & $4.76 \pm 1.79$ & $12.18 \pm 19.67$ & $6.82 \pm 2.65$ & $56.25 \pm 38.11$ \\
\hline
\end{tabular}




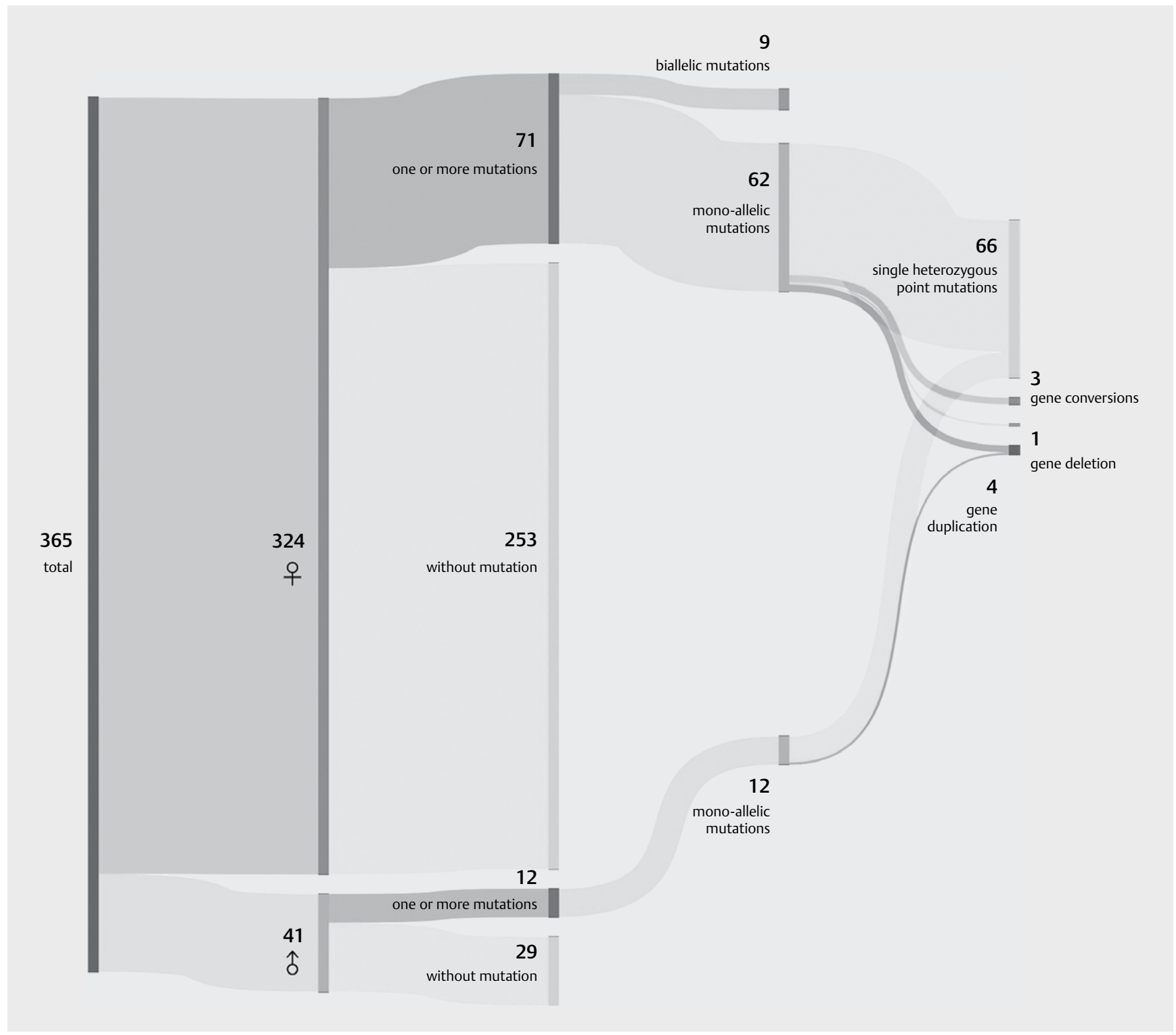

- Fig. 1 Sankey-Diagram of investigated patients depicting apportionment of mutations and gender.

stimulated and basal $170 H P(\triangle 170 H P 30)$, was 0.971 . Again, calculating quotients of different $17 \mathrm{OHP}$ values showed to be a very weak test of which none refuted the null hypothesis ( $\vee$ Table 3 ).

As one might expect, the AUCs for the respective tests are even higher when used for only identifying patients with compound heterozygous mutations that show a combination of a mild and a severe mutation ( $>$ Table 1S, Supplementary Material).

A 60 min after stimulation 170HP (170HP60) value of above $10 \mu \mathrm{g} / \mathrm{l}$ is described as diagnostic for a homozygous condition [24]. However, it is of note that this cut-off was established before the introduction of molecular genetic analysis of the CYP21 gene. Previous publications have noted an overlap with heterozygous carriers for 170 HP6 $0>10 \mu \mathrm{g} /$ l. This can also be observed in our cohort of the genotyped patients. 18 patients fulfilled the criterion $170 \mathrm{HP} 60>10 \mu \mathrm{g} / \mathrm{l}$. Of these, 8 (44\%) showed biallelic mutations, 7 (39\%) were heterozygous and in $3(17 \%)$ genotyping revealed no mutation. The three patients which showed no mutations had 170 HP60 values of $11.6,10.6$ and $10.5 \mu \mathrm{g} / \mathrm{l}$ but no further genotyping for other genes was performed. Previously it has been reported, that the $170 \mathrm{HP} 60>10 \mu \mathrm{g} / \mathrm{I}$ cut-off yielded no false negatives [25]. In our cohort one homozygous patient had 170HP values $60 \mathrm{~min}$ after stimulation below $10 \mu \mathrm{g} / \mathrm{l}$.

As an ideal test we recommend calculating the difference between 30 min stimulated and basal $170 H P$ values $(\Delta 170 H P 30)$ and to use a cut-off of $9.4 \mu \mathrm{g} / \mathrm{l}$. This criterion applied to 9 patients. $8 \mathrm{had}$ confirmed bi-allelic mutations and 1 carried a p.Arg339His and p.Pro453Ser mutation. Due to lack of segregation analysis they could not be confirmed to be located in trans. Sensitivity is equal for the two cut-offs (88.9\%) whereas specificity is slightly higher for $\triangle 170 H P 30$ with $99.7 \%$ compared to $99.2 \%$ for the $170 H P 60$ cutoff. The LR + is 296.3 for the $\triangle 170 H P 30$ cut-off compared to 111.1 for the $170 H P 60$ cut-off. The LR- is equal for the two with 0.111 . 
- Table 2 Detected Mutations and respective frequencies.

\begin{tabular}{|c|c|c|}
\hline Mutation & Count & $\begin{array}{l}\text { Classification } \\
\text { (Mild/Severe) }\end{array}$ \\
\hline p.Val281Leu (CYP21A2*15) & 36 & Mild \\
\hline p.Gln318Stop (CYP21A2 * 17) & 17 & Severe \\
\hline p.Pro453Ser (CYP21A2* 19) & 8 & Mild \\
\hline IVS2-13 A/C>G (CYP21A2 * 9) & 5 & Severe \\
\hline p.Pro482Ser (CYP21A2*61) & 3 & Mild \\
\hline p.lle172Asn (CYP21A2 * 11) & 3 & Severe \\
\hline $\begin{array}{l}-103 A>G(C Y P 21 A 2 * 20 D \text { without } \\
\text { c. }-126 C>T, \text { c. }-113 G>A, \text { c. }-110 T>C,)\end{array}$ & 3 & Mild \\
\hline p.Arg479Leu (CYP21A2* 100) & 2 & Mild \\
\hline 8bp-Deletion (CYP21A2 * 10) & 2 & Severe \\
\hline Gene deletion & 2 & Severe \\
\hline $\begin{array}{l}-126 C>T(C Y P 21 A 2 * 20 D \text { without, } \\
\text { c. }-113 G>A, \text { c. }-110 T>C, c .-103 A>G)\end{array}$ & 2 & Mild \\
\hline $\begin{array}{l}\text { c.-126C>T, c. }-113 G>A, \text { c. }-110 T>C, \text { c. } \\
103 A>G(C Y P 21 A 2 * 20 D)\end{array}$ & 1 & Mild \\
\hline $\begin{array}{l}-110 \mathrm{~T}>\mathrm{C} ;-113 \mathrm{G}>\mathrm{A} ;-126 \mathrm{C}>\mathrm{T}(\mathrm{CY}- \\
\mathrm{P} 21 \mathrm{~A} 2 * 20 \mathrm{D} \text { without }-103 \mathrm{~A}>\mathrm{G})\end{array}$ & 1 & Mild \\
\hline $\begin{array}{l}\text { p.lle172Asn, p.Ile236Asn, pVal237Glu, } \\
\text { p,Met239Lys (CYP21A2* 20F without } \\
\text { V281Leu)) }\end{array}$ & 1 & Severe \\
\hline p.Pro30Leu (CYP21A2 * 15) & 1 & Mild \\
\hline p.Arg356Trp (CYP21A2* 18) & 1 & Severe \\
\hline${ }^{*}$ IVS2-13AG >A & 1 & Severe ${ }^{1}$ \\
\hline p.Ala434Val (CYP21A2* 95) & 1 & Severe \\
\hline 8bp-Deletion, pGln318Stop & 1 & Severe \\
\hline p.Arg339His, p.Pro453Ser (CYP21A2* 24) & 1 & Mild \\
\hline
\end{tabular}

Count refers to number of alleles with respective mutation, not patients. Hence bi-allelic patients are counted twice. Unless stated otherwise, classification into mild and severe mutations is based on Data from the Parmacogen Variation (PhramVar) Consortium. ${ }^{2}$ 1. Neocleous V, Fanis P, Phylactou LA \& Skordis N. Genotype Is Associated to the Degree of Virilization in Patients With Classic Congenital Adrenal Hyperplasia. Front Endocrinol (Lausanne) 20189 733. 2. Gaedigk A, Ingelman-Sundberg M, Miller NA, Leeder JS, Whirl-Carrillo M, Klein TE \& PharmVar Steering C. The Pharmacogene Variation (PharmVar) Consortium: Incorporation of the Human Cytochrome P450 (CYP) Allele Nomenclature Database. Clin Pharmacol Ther 2018103 399-401.

In both tests one patient with mutations affecting both parental alleles remained unrecognised. This patient showed a $\triangle 170 H P 30$ of $3.6 \mu \mathrm{g} /$ and a homozygous $-126 C>$ T promoter mutation in the CYP21A2 gene. The $-126 C>T$ mutation is commonly associated with $-103 \mathrm{~A}>\mathrm{G},-110 \mathrm{~T}>\mathrm{C}$ and $-113 \mathrm{G}>\mathrm{A}$ mutations, which were not found in this patient. However, in vitro experiments showed that the $-126 C>$ T mutation itself can reduce CYP21A2 transcriptional activity to $52 \%$ [26], which suggests a pathogenic effect correlating to NCCAH.

For the identification of patients with at least one mutated allele or only bi-allelic mutations we therefore recommend the calculation of two different values id est for sum 170 HPstim and $\Delta 170 H P 30$. For simplicity a physician might favour an approach with a single calculation or test with two separate cut-off values instead. In this case we propose the calculation of $\triangle 170 H P 60$ values.

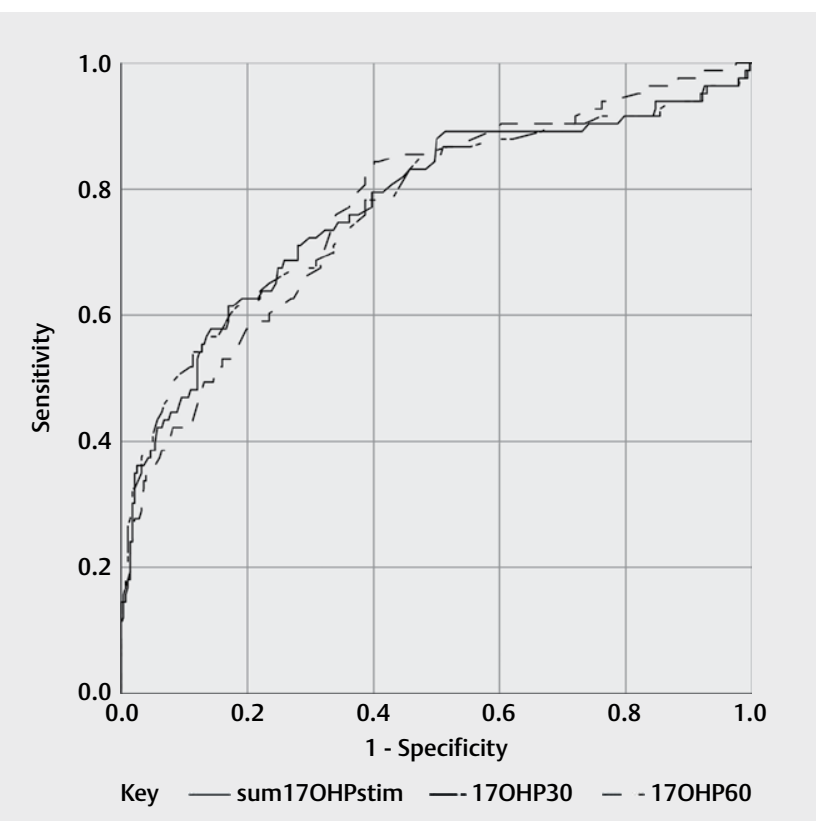

Fig. 2 ROC with the three best performing test for identification of patients with at least one mutated CYP21A2 allele.

For identifying patients with at least one mutated parental allele the best cut-off point is $3.6 \mu \mathrm{g} / \mathrm{l}$. Compared to the sum $17 \mathrm{OHP}$ stim cut-off of $10.1 \mu \mathrm{g} /$ I this cut-off has a higher sensitivity (75.9\%) and a lower specificity (66.0\%). Due to the higher sensitivity the number of false negatives is smaller with just 19 compared to 24 . The false negative rate is 0.229 for the $\triangle 170 H P 60$ cut-off. This obviously comes with the trade-off of more FPs. These were 97 and 79 for $\triangle 170 H P 60$ and sum $170 H$ Pstim respectively.

When using the $\triangle 170 H P 60$ test to identify patients with bi-allelic mutations we recommend a cut-off of $10 \mu \mathrm{g} / \mathrm{l}$. It resulted in values for sensitivity and specificity of $88.9 \%$ and $99.2 \%$ respectively. Sensitivity is equal to that of the appropriate $\triangle 170 H P 30$ cutoff. Specificity was $99.7 \%$ and therefore a bit higher in the $\triangle 170 H P 30$ test.

\section{Discussion}

In this study we assessed 12 different tests to identify individuals with heterozygous and bi-allelic CYP21A2 mutations, based on ACTH-tests and molecular genetic analysis of 365 patients with symptoms of hyperandrogenism. For identifying carriers of at least one CYP21A2 mutation we advocate calculating the sum of $30 \mathrm{~min}$ and $60 \mathrm{~min}$ postACTH stimulated values (sum17OHPstim) and to apply a cut-off of $>10.1 \mu \mathrm{g} / \mathrm{l}$. The difference between $17 \mathrm{OHP} 30$ min after stimulation and basal values $(\triangle 17 \mathrm{OHP} 30)$ above $9.4 \mu \mathrm{g} / \mathrm{l}$ proved to be the most effective for identifying patients with bi-allelic mutations. As a single test with two different cut-offs for detecting either carriers or NCCAH patients can be desirable in practice due to the simpler workflow we propose calculating the difference between basal and 17OHP values 60 min after $A C T H$ was given $(\triangle 170 H P 60)$. As a cut-off to identify carriers of heterozygous mutations we propose elevating the pre-existing $\triangle 170 H P 60$ cut-off from $2.5 \mu \mathrm{g} / \mathrm{l}[19]$ to $3.6 \mu \mathrm{g} / \mathrm{l}$. We ob- 
- Table 3 Information from Receiver operating characteristic for 12 investigative tests for identifying patients with at least one or two mutated alleles.

\begin{tabular}{|c|c|c|c|c|c|}
\hline & \multirow[t]{2}{*}{ Test Variable } & \multirow[t]{2}{*}{$\begin{array}{l}\text { Area under the } \\
\text { curve (AUC) }\end{array}$} & \multirow[t]{2}{*}{$\begin{array}{l}\text { Asymptotic } \\
\text { Significance }\end{array}$} & \multicolumn{2}{|c|}{$\begin{array}{l}\text { Asymptotic } 95 \% \text { Confidence } \\
\text { Interval }\end{array}$} \\
\hline & & & & Lower Bound & Upper Bound \\
\hline \multirow[t]{12}{*}{ At least one mutated parental allele } & 17OHPBasal & 0.574 & 0.040 & 0.498 & 0.650 \\
\hline & 17OHP30 & 0.772 & 0.000 & 0.707 & 0.836 \\
\hline & $17 \mathrm{OHP} 60$ & 0.768 & 0.000 & 0.704 & 0.831 \\
\hline & $\triangle 170 H$ P30 & 0.760 & 0.000 & 0.698 & 0.823 \\
\hline & $\triangle 17 \mathrm{OHP} 60$ & 0.771 & 0.000 & 0.712 & 0.831 \\
\hline & $\Delta 170 H$ Pstim & 0.604 & 0.004 & 0.529 & 0.679 \\
\hline & Sum17OHP30 & 0.739 & 0.000 & 0.673 & 0.806 \\
\hline & Sum17OHP60 & 0.737 & 0.000 & 0.671 & 0.803 \\
\hline & Sum 170HPstim & 0.774 & 0.000 & 0.710 & 0.838 \\
\hline & Ratio 17OHP30 & 0.600 & 0.006 & 0.527 & 0.673 \\
\hline & Ratio 17OHP60 & 0.604 & 0.004 & 0.531 & 0.677 \\
\hline & Ratio 170HPstim & 0.495 & 0.885 & 0.425 & 0.565 \\
\hline \multirow{12}{*}{$\begin{array}{l}\text { Only one mutated parental allele } \\
\text { (heterozygous) }\end{array}$} & 17OHPBasal & 0.529 & 0.039 & 0.435 & 0.452 \\
\hline & 17ОНР30 & 0.728 & 0.035 & 0.000 & 0.658 \\
\hline & $17 \mathrm{OHP60}$ & 0.726 & 0.035 & 0.000 & 0.658 \\
\hline & $\triangle 17 \mathrm{OHP} 30$ & 0.713 & 0.034 & 0.000 & 0.646 \\
\hline & $\triangle 170 H P 60$ & 0.727 & 0.033 & 0.000 & 0.663 \\
\hline & $\Delta 17$ OHPstim & 0.567 & 0.039 & 0.076 & 0.491 \\
\hline & Sum 17OHP30 & 0.694 & 0.036 & 0.000 & 0.623 \\
\hline & Sum 17OHP60 & 0.694 & 0.036 & 0.000 & 0.624 \\
\hline & Sum 170HPstim & 0.731 & 0.035 & 0.000 & 0.662 \\
\hline & Ratio 17OHP30 & 0.592 & 0.039 & 0.015 & 0.516 \\
\hline & Ratio 170HP60 & 0.595 & 0.038 & 0.012 & 0.519 \\
\hline & Ratio $170 H$ Pstim & 0.489 & 0.036 & 0.778 & 0.418 \\
\hline \multirow[t]{12}{*}{ Both parental alleles mutated (bi-allelic) } & 17OHPBasal & 0.843 & 0.000 & 0.669 & 1.000 \\
\hline & $17 \mathrm{OHP30}$ & 0.955 & 0.000 & 0.871 & 1.000 \\
\hline & $17 \mathrm{OHP60}$ & 0.939 & 0.000 & 0.827 & 1.000 \\
\hline & $\Delta$ 170HР30 & 0.971 & 0.000 & 0.919 & 1.000 \\
\hline & $\triangle 17 \mathrm{OHP60}$ & 0.956 & 0.000 & 0.877 & 1.000 \\
\hline & $\Delta 170 H$ Pstim & 0.808 & 0.002 & 0.588 & 1.000 \\
\hline & Sum $17 \mathrm{OHP} 30$ & 0.943 & 0.000 & 0.837 & 1.000 \\
\hline & Sum 17OHP60 & 0.929 & 0.000 & 0.798 & 1.000 \\
\hline & Sum 17OHPstim & 0.947 & 0.000 & 0.850 & 1.000 \\
\hline & Ratio $170 \mathrm{HP} 30$ & 0.613 & 0.244 & 0.397 & 0.83 \\
\hline & Ratio 17OHP60 & 0.621 & 0.214 & 0.394 & 0.848 \\
\hline & Ratio $170 H$ Pstim & 0.533 & 0.735 & 0.311 & 0.755 \\
\hline
\end{tabular}

served the $\triangle 170 H P 60$ cut-off for bi-allelic patients to be optimal at $10 \mu \mathrm{g} / \mathrm{l}$.

One of the major strengths of this study is the relatively large number of ACTH-tested and genotyped patients of a paediatric cohort (1-20 years) with clinical signs of hyperandrogenism. However, several limitations must be acknowledged. 17OHP measurements were performed using RIA, which have been shown to deliver measurements that tend to be substantially higher compared to those retrieved by LC-MS/MS [27], the gold standard for 170HP measurements [1]. Nevertheless, the results can be of guidance in the clinical routine, as LC-MS/MS has a higher cost and longer turnaround times, and thus the use of RIA still reflects the diagnostic routine in many clinical settings. In addition, the current Endocrine Society guidelines do not offer recommendations on thresholds for $170 \mathrm{HP}$ values measured through RIA in the context of NCCAH diagnostics and carrier identification [1].

Considering an intra-assay variation of $4.6 \%$ for the RIA used to determine 170HP levels, one should consider to what extent the variation between the compared tests can be attributed to variance in laboratory results. $170 \mathrm{HP}$ measurements may also have 
been influenced by patients' meals prior to ACTH-testing as patients were non-fasting and meals are known to influence cortisol production [28-30]. The non-fasting interventions reflect data retrieved in the clinical routine and the effect is most likely minor as reported by Klose et al. [31] but this influence should be acknowledged.

Taken together the intra- and interassay variations of RIAs, as well as possible effects due to food intake and possible menstrual cycle confounders may reduce the practical difference between the investigated tests. The AUCs of the three best performing tests for identifying those patients with at least one mutated parental allele (Sum170HPstim, 170HP30, 17 OHP60) are very similar ( Fig. 2) with $0.774,0.772$ and 0.771 , respectively. In the clinical routine they may indeed all be equivalent in their diagnostic capacity.

The AUCs may also be slanted by cases with p.Gln318Stop mutations attributed to the group of heterozygous patients, as localization of the mutation on an allele carrying two CYP21A2 copies reduces the pathogenicity of this mutation and older cases have not been tested by MLPA to determine the co-occurrence of a duplicated haplotype.

The patients in this study were selectively analysed for mutations in CYP21A2, thus other mutations causing $C A H$ such as in $C Y$ $P 11 B 1$ or CYP17A1 are not accounted for. Mutations in these genes generally do not cause NCCAH [32] but it should be kept in mind that when aiming to identify carriers, the thresholds only apply for screening of 21-hydroxylase deficiency.

The CAH causing mutations besides CYP21A2 are also a possible reason for the occurrence of elevated $\mathrm{ACTH}$-test responses and negative molecular genetic analysis in this study. However, it is unlikely that this is the only explanation for negative genetic tests and high $\triangle 170 H P$ values. 132 Patients had $\Delta 170 H P 60>4 \mu \mathrm{g} /$ and of these 79 (60\%) had negative genetic tests. Cinar et al. reported that PCOS patients had significantly higher ACTH stimulated $170 \mathrm{HP}$ levels after 60 min than controls [33]. Though this is not supported by an investigation by Luboshitzky et al. [34], it demonstrates the necessity to identify possible reasons for increased $17 \mathrm{OHP}$ response during $\mathrm{ACTH}$-testing besides $\mathrm{CAH}$.

Though generally elevated, the significant overlap of responses to ACTH stimulation between individuals with and without $C Y$ P21A2 mutations demonstrates the superiority of molecular genetic analysis in identifying heterozygotes. Similarly, also for bi-allelic patients genotyping remains necessary for making the final diagnosis of NCCAH. In the future, with continuously declining costs of molecular genetic analysis, it may become more resourceful to perform molecular genetic analysis initially, should symptoms apply. Considering especially that ACTH-tests may need to be repeated, additional costs can arise. To evaluate the adrenal reserve an ACTH-test could nonetheless be of relevance after genetic diagnosis in confirmed bi-allelic patients.

In individual cases, sequencing without prior ACTH-testing can already be adequate today when definitive molecular genetic results are needed, especially in the context of family planning and genetic counselling. For example, when the wish to have children exists and the patient presents with hyperandrogenemia, there is a notable family anamnesis or to determine carrier state of a patients' spouses. This is especially important as half of NCCAH males are asymptomatic and can otherwise remain unrecorgnised [25]. On the basis of genetic counselling prenatal therapy or, in the fu- ture, genotyping using cell-free fetal DNA may be offered when the pregnancy is established and the neonate is at risk of CAH [35]. Therefore, it remains essential to critically revaluate diagnostic schemas with evolving research and changing costs and access to diagnostic methods such as LC-MS/MS and sequencing technologies to ensure optimal patient care and clinical decisionmaking.

\section{Ethics}

In 2006 we made a request at the Ruhr-Universität Bochum, if an approval of an ethics committee will be needed for the envisaged clinical trial. Since we conducted an evaluation of inevitable clinical routine tests, we received a negative answer in this regard. After the introduction of the German Act of Gene Diagnostics ("Gendiagnostikgesetz") in Germany in 2009, we have not requested an ethics vote. Consent has been obtained from all parents after full explanation of the purpose and nature of all procedures used.

\section{Funding}

A. Richter-Unruh received honoraria and funding from Ferring, Hexal/Sandoz/Novartis, NovoNordisk, Ipsen, Kyowa Kirin and Merck/Serono.

Specific grant numbers were not assigned.

\section{Author Statement}

J. Meinel designed and performed the analysis and prepared the manuscript with assistance of A. Richter-Unruh. T. Haverkamp gathered the data, contributed the molecular genetic expertise and commented on the manuscript. F. Wünsche supported in the evaluation of the laboratory chemical data on the course and measurement procedures during the study and commented on the manuscript. A. Richter-Unruh conceptualized the idea and supervised the work's progression.

\section{Declaration of Interest}

The authors declare that there is no conflict of interest that could be perceived as prejudicing the impartiality of the research reported.

\section{References}

[1] Speiser PW, Arlt W, Auchus RJ et al. Congenital adrenal hyperplasia due to steroid 21-hydroxylase deficiency: An Endocrine Society Clinical Practice Guideline. J Clin Endocrinol Metab 2018; 103: 4043-4088. DOI: 10.1210/jc.2018-01865

[2] Merke DP. Approach to the adult with congenital adrenal hyperplasia due to 21-hydroxylase deficiency. J Clin Endocrinol Metab 2008; 93: 653-660. DOI: 10.1210/jc.2007-2417

[3] Gidlof S, Falhammar H, Thilen A et al. One hundred years of congenital adrenal hyperplasia in Sweden: a retrospective, population-based cohort study. Lancet Diabetes Endocrinol 2013; 1: 35-42. DOI: 10.1016/S2213-8587(13)70007-X 
[4] Gidlof S, Wedell A, Guthenberg C et al. Nationwide neonatal screening for congenital adrenal hyperplasia in sweden: A 26-year longitudinal prospective population-based study. JAMA Pediatr 2014; 168: 567-574. DOI: 10.1001/jamapediatrics.2013.5321

[5] Fiet ], Gueux B, Gourmelen M et al. Comparison of basal and adrenocorticotropin-stimulated plasma 21-deoxycortisol and 17-hydroxyprogesterone values as biological markers of late-onset adrenal hyperplasia. J Clin Endocrinol Metab 1988; 66: 659-667. DOI: 10.1210/jcem-66-4-659

[6] Witchel SF, Lee PA. Identification of heterozygotic carriers of 21-hydroxylase deficiency: Sensitivity of ACTH stimulation tests. Am J Med Genet 1998; 76: 337-342

[7] Kreutzmann DJ, Cowell CT, Howard NJ et al. Congenital adrenal hyperplasia family studies using the short ACTH test. Australian Paediatric Journal 1989; 25: 340-345

[8] Bachega TA, Brenlha EM, Billerbeck AE et al. Variable ACTH-stimulated 17-hydroxyprogesterone values in 21-hydroxylase deficiency carriers are not related to the different CYP21 gene mutations. J Clin Endocrinol Metab 2002; 87: 786-790. DOI: 10.1210/jcem.87.2.8247

[9] Knochenhauer ES, Cortet-Rudelli C, Cunnigham RD et al. Carriers of 21-hydroxylase deficiency are not at increased risk for hyperandrogenism. J Clin Endocrinol Metab 1997; 82: 479-485. DOI: 10.1210/ jcem.82.2.3759

[10] Dacou-Voutetakis C, Dracopoulou M. High incidence of molecular defects of the CYP21 gene in patients with premature adrenarche. J Clin Endocrinol Metab 1999; 84: 1570-1574. DOI: 10.1210/ jcem.84.5.5683

[11] Kulle AE, Riepe FG, Hedderich ] et al. LC-MS/MS based determination of basal- and ACTH-stimulated plasma concentrations of 11 steroid hormones: implications for detecting heterozygote CYP21A2 mutation carriers. Eur J Endocrinol 2015; 173: 517-524. DOI: 10.1530/ EJE-14-1084

[12] Bidet M, Bellanne-Chantelot C, Galand-Portier MB et al. Clinical and molecular characterization of a cohort of 161 unrelated women with nonclassical congenital adrenal hyperplasia due to 21-hydroxylase deficiency and 330 family members. J Clin Endocrinol Metab 2009; 94: 1570-1578. DOI: 10.1210/jc.2008-1582

[13] Tardy V, Forest M, De Rougemont A et al. Detection of heterozygotes for 21-hydroxylase deficiency: validation of 21-deoxycortisol after ACTH test by sequencing of the entire CYP21 gene. Horm Res Paediatr 2005; 64: 41-42

[14] Costa-Barbosa FA, Tonetto-Fernandes VF, Carvalho VM et al. Superior discriminating value of ACTH-stimulated serum 21-deoxycortisol in identifying heterozygote carriers for 21-hydroxylase deficiency. Clin Endocrinol (Oxf) 2010; 73: 700-706. DOl: 10.1111/j.1365-2265. 2010.03871.x

[15] Kulle AE, Riepe FG, Melchior D et al. A novel ultrapressure liquid chromatography tandem mass spectrometry method for the simultaneous determination of androstenedione, testosterone, and dihydrotestosterone in pediatric blood samples: Age- and sex-specific reference data. J Clin Endocrinol Metab 2010; 95: 2399-2409

[16] Escobar-Morreale HF, Sanchon R, San Millan JL. A prospective study of the prevalence of nonclassical congenital adrenal hyperplasia among women presenting with hyperandrogenic symptoms and signs. J Clin Endocrinol Metab 2008; 93: 527-533. DOI: 10.1210/jc.2007-2053

[17] Nimkarn S, Gangishetti PK, Yau M et al. 21-Hydroxylase-Deficient Congenital Adrenal Hyperplasia. In: Pagon RA, Adam MP, Ardinger HH, Eds. GeneReviews(R). Seattle (WA): University of Washington, Seattle University of Washington, Seattle. All rights reserved. 1993

[18] Schenk D. Prämature Pubarche - ACTH-Test und Mutationsanalyse des 21-Hydroxylasegens; Dissertation, LMU München. 2005
[19] Weil ], Bidlingmaier F, Sippell WG et al. Comparison of two tests for heterozygosity in congenital adrenal hyperplasia (CAH). Acta endocrinologica 1979; 91: 109-121

[20] New MI, Lorenzen F, Lerner AJ et al. Genotyping steroid 21-hydroxylase deficiency: hormonal reference data. J Clin Endocrinol Metab 1983; 57 : 320-326. DOI: 10.1210/jcem-57-2-320

[21] [Anonymous] In DIAsource ImmunoAssays S.A.

[22] Gaedigk A, Ingelman-Sundberg M, Miller NA et al. The Pharmacogene Variation (PharmVar) Consortium: Incorporation of the Human Cytochrome P450 (CYP) Allele Nomenclature Database. Clin Pharmacol Ther 2018; 103: 399-401. DOI: 10.1002/cpt.910

[23] Froud R, Abel G. Using ROC curves to choose minimally important change thresholds when sensitivity and specificity are valued equally: the forgotten lesson of pythagoras. theoretical considerations and an example application of change in health status. PLoS One 2014; 9: e114468. DOI: 10.1371/journal.pone.0114468

[24] Moran C, Azziz R. 21-hydroxylase-deficient nonclassic adrenal hyperplasia: the great pretender. Seminars in reproductive medicine 2003; 21: 295-300. DOI: 10.1055/s-2003-43307

[25] Livadas S, Dracopoulou M, Dastamani A et al. The spectrum of clinical, hormonal and molecular findings in 280 individuals with nonclassical congenital adrenal hyperplasia caused by mutations of the CYP21A2 gene. Clin Endocrinol (Oxf) 2015; 82: 543-549. DOI: 10.1111/ cen. 12543

[26] Araujo RS, Mendonca BB, Barbosa AS et al. Microconversion between CYP21A2 and CYP21A1P promoter regions causes the nonclassical form of 21-hydroxylase deficiency. J Clin Endocrinol Metab 2007; 92: 4028-4034. DOI: 10.1210/jc.2006-2163

[27] Chesover AD, Millar H, Sepiashvili L et al. Screening for nonclassic congenital adrenal hyperplasia in the era of liquid chromatographytandem mass spectrometry. J Endocr Soc 2020; 4: bvz030. DOI: $10.1210 /$ jendso/bvz030

[28] Brandenberger G, Follenius M, Hietter B. Feedback from meal-related peaks determines diurnal changes in cortisol response to exercise. J Clin Endocrinol Metab 1982; 54: 592-596. DOI: 10.1210/jcem-54-3592

[29] Pasquali R, Biscotti D, Spinucci G et al. Pulsatile secretion of ACTH and cortisol in premenopausal women: effect of obesity and body fat distribution. Clin Endocrinol (Oxf) 1998; 48: 603-612. DOI: 10.1046/j.1365-2265.1998.00458.x

[30] Quigley ME, Yen SS. A mid-day surge in cortisol levels. J Clin Endocrinol Metab 1979; 49: 945-947. DOI: 10.1210/jcem-49-6-945

[31] Klose M, Lange M, Rasmussen AK et al. Factors influencing the adrenocorticotropin test: role of contemporary cortisol assays, body composition, and oral contraceptive agents. J Clin Endocrinol Metab 2007; 92: 1326-1333. DOI: 10.1210/jc.2006-1791

[32] Krone N, Arlt W. Genetics of congenital adrenal hyperplasia. Best Pract Res Clin Endocrinol Metab 2009; 23: 181-192. DOI: 10.1016/j. beem.2008.10.014

[33] Cinar N, Harmanci A, Aksoy DY et al. Adrenocortical steroid response to ACTH in different phenotypes of non-obese polycystic ovary syndrome. J Ovarian Res 2012; 5: 42. DOI: 10.1186/1757-2215-5-42

[34] Luboshitzky R, Ishai A, Shen-Or Z et al. Evaluation of the pituitaryadrenal axis in hyperandrogenic women with polycystic ovary syndrome. Neuro endocrinology letters 2003; 24: 249-254

[35] Dorr HG, Binder G, Reisch N et al. Experts' Opinion on the Prenatal Therapy of Congenital Adrenal Hyperplasia (CAH) Due to 21-Hydroxylase Deficiency - Guideline of DGKED in cooperation with DGGG (S1-Level, AWMF Registry No. 174/013, July 2015). Geburtshilfe Frauenheilkd 2015; 75: 1232-1238. DOI: 10.1055/s-0041-109717 